\title{
UNA VISITA A LOS CAMPAMENTOS DE REFUGIADOS Y REFUGIADAS SAHARAUIS EN TINDOUF (ARGELIA): DERECHO, POLITTICA Y CAPITAL EN LOS CUERPOS
}

\author{
VISITING THE SAHARA OF REFUGEES: LAW, POLITICS AND \\ CAPITAL IN HUMAN BODIES
}

Medina Martín, Rocío;

Gómez Justo, Juan Carlos;

García Sánchez, Diego y

Rodríguez Morillo, Manuel Jesús
Recibido: septiembre de 2011.

Aceptado: noviembre de 2011.

«El desierto es el delirio geográfico-político»

Gilles Deleuze

Palabras clave: Sáhara Occidental, Torturas, Derecho Internacional, Neoliberalismo, Explotación de recursos naturales.

Keywords: Western Sahara, Tortures, International Law, Neoliberalism, Exploitation of Natural Resources

Resumen: Tras un año de existencia del grupo de estudios «Saharupo» sobre el conflicto saharaui y tras la realización de su primer desplazamiento a los campos de refugiados y refugiadas saharauis en Tindouf, Argelia, los miembros del grupo, mayoritariamente estudiantes de derecho y ciencias políticas, pretenden dar cuenta, a través del presente testimonio, de las reflexiones compartidas y colectivas que consideran como los principales aportes que a su aprendizaje académico ha realizado tanto la pertenencia al grupo de estudios y como trabajo de campo realizado.

Abstract: The study group on the Sahara conflict «Saharaupo» was created one year ago. After their first trip to the saharawi refugee camps in Tindouf, Algeria, the members of this group have spoken. They are mostly students of Law and Political Sciences and, with this testimony, they want to share the most important reflections of their experience in both the study group and the field research, as well as the way it has contributed to their academic learning. 


\section{De cómo surgió y se organizó el grupo de trabajo: la indignación como espacio para aprender a aprender de otro modo.}

Desmantelamiento y ataque al Campamento de la Dignidad "Gdeim Izik», 8 de noviembre de 2010. Aproximadamente 20.000 saharauis instalados en miles de jaimas a las afueras de la ciudad de El Aaiún reivindicando el derecho a tener a derechos, como decía Hannah Arendt. Llamadas de teléfono que nos convocaban a la primera reunión, en la universidad se debía hacer algo, no era posible pasar por alto lo ocurrido, mirar hacia otro lado, una vez más. ¿Dónde empieza si no la universidad crítica y comprometida socialmente? Así conocimos Sáhara Occidental, siete meses después aterrizamos en los campos de refugiados y refugiadas saharauis en Tindouf, Argelia. Ninguno de los compañeros y compañeras del equipo tenía consciencia de lo que significaría para nosotros aquel acontecimiento como estudiantes y aprendices en las ciencias sociales.

La mayoría del grupo cursaba tercero de la doble licenciatura en derecho y ciencias políticas y de la administración, una compañera de postgrado politóloga, curtida en los movimientos sociales en El Salvador y una profesora del área de filosofía del derecho. Once en total. Casi todos y todas en conexión con movimientos políticos y sociales, en una gama de colores muy complicada de mezclar, pero interrogando, en común, las lógi- cas de nuestros sistemas políticos autodenominados como representativos y las palpables distancias entre el pensamiento político y el mundo que nos rodea, entre las retóricas humanistas y la misantropía contemporánea.

Tras el ataque al campamento, la primera actividad organizada conjuntamente entre profesorado y alumnado consistió en un seminario abierto al público en el paraninfo de la Universidad: «El conflicto saharaui: la voz de sus agentes políticos y sociales». Fue un primer acercamiento directo al tema para la mayoría del grupo y para los casi cien asistentes. Y demasiadas palabras claves: bancos pesqueros, derecho internacional, torturas, cooperación, intifada, movimientos sociales, nueve millones de minas anti-personas, campos de refugiados, colonización, relaciones internacionales, mujeres, violación de derechos humanos, socio preferente, un muro de 2.720 kms, Minurso, marcha verde, neoliberalismo, movimiento de liberación, islam, territorios no autónomos, expoliación de recursos, resistencia... un puzle interminable que, a partir de ese día, decidimos intentar comprender.

La propuesta de reunirnos todas las semanas y compartir textos sobre el conflicto saharaui, pronto precedió a la de realizar una base de datos, encargar material bibliográfico, rastrear y compilar material audiovisual, tomar contacto con los movimientos sociales andaluces... Así, de Jueves en Jueves, sin apenas darnos cuenta, se construyó el grupo de estudios sobre el conflicto saharaui en nuestra universidad, en el seno del Laboratorio de Ideas y Prácticas Políticas. 
Las primeras sesiones de trabajo se usaron materiales más genéricos e interdisciplinares, en un intento de ir acercándonos a una panorámica más amplia del conflicto. En la medida que iban avanzando las lecturas, cada uno de nosotros y nosotras fue escogiendo aquellas áreas o ámbitos de la temática saharaui que más nos seducían e interesaban. De este modo surgieron las diferentes temáticas dentro del grupo: Vulneración de los derechos humanos en los territorios ocupados, Islam y derecho en el pueblo saharaui, Mujeres saharauis y su rol político-social, La historia de la colonización española en el Sáhara Occidental, Organización interna y funcionamiento del Frente Polisario y Expoliación de recursos en los territorios ocupados.

Cada miembro del grupo de estudios avanzaba en su área y compartía en los seminarios semanales con los compañeros/as los hallazgos y avances obtenidos en los rastreos documentales. No obstante, el objetivo final de las sesiones conjuntas consistía en encontrar los puntos de conexión y relación entre las diversas áreas de estudio de cada miembro, lo que supuso una metodología cooperativa y relacional con un elevado contenido reflexivo. De esta manera, pronto entendimos que aquella organización en diversos ámbitos de trabajo fue una pequeña jugada metodológica para ir acercándonos al tema de manera más sencilla, con cierta reducción en los enfoques y aparente minimización de actores sociales y políticos. El objetivo final de los encuentros en los seminarios era ir construyendo una mirada colectiva y compleja del conflicto. Tras varios me- ses de investigación, el grupo de estudios se llamó SaharUpo y se convirtió en un espacio académico sui generis, un cruce de diferentes caminos y disciplinas al que llegábamos todas las mañanas de los Jueves. Será difícil, como estudiantes universitarios y universitarias, volver a pensar de manera inconexa el derecho, el poder, la política y la economía.

Desde que comenzamos a estudiar en la universidad como alumnos y alumnas en primer curso, queríamos aprender «política» y «derecho», nos parecían herramientas fundamentales para entender y transformar el sistema político y económico mundial. Comienzan las clases, los primeros debates; todo es nuevo, todo impresiona. Descubres autores, los profesores te recomiendan lecturas, asistes a conferencias. La expectación que ofrecía esta nueva etapa de la vida parecía cumplirse. Los y las que tenemos el privilegio de llegar a vivir esta etapa universitaria, indudablemente, transformamos nuestra manera de ver la realidad. Pero esta experiencia tan imaginada en nuestras mentes poco a poco comenzó a decepcionarnos. A medida que pasaban los meses y los cursos, apreciábamos que en muchos casos los/ as profesoras/as no enseñan, simplemente reproducen, te ofrecen consumir productos, acumular información que no pretenden que entiendas. ¿Nos enseñan herramientas para que podamos construir escenas o nos muestran el final de la película? Como dice un proverbio chino «Si das pescado a un hombre hambriento, le nutres una jornada. Si le enseñas a pescar, le nutrirás toda la vida». En muchas ocasiones esta es la reali- 
dad, nos dan el pescado pero no nos dicen ni cómo ni dónde se pescó, ni siquiera nos dicen si es comestible. Estudiamos y memorizamos a los clásicos, pero pocas veces buscamos en ellos claves para conocer, comprender y acompañar a los colectivos políticos que ahora y en estos tiempos están cuestionando a los poderes establecidos. Nos enseñan teoría política pero muy poca realidad política, y mucho menos si de experiencias que resisten al "status quo» se trata. Parece que el «laboratorio» de mentes, ideas y emociones que se suponía que era el aula, ya no lo es tanto. Quizás, ahora más que nunca, las mentes de probeta están proliferando.

Por estas razones, la experiencia como miembros del SaharUpo ha sido extraordinaria, aún sin el trabajo de campo en los campamentos de refugiados y refugiadas, ya supuso aprender a aprender de otro modo. Por irrelevante que parezca, ya fue un alivio salir de aula. Escapar de un espacio jerárquico de educación donde desde la tarima se enseña a los/as pupilos/as. Salir de este formato de relación pedagógica, posibilitó, entre otros motivos, horizontalizar la relación entre la docente y el alumnado. Sin embargo, lo más determinante para el grupo consistía en que no se trataba de recibir recetas o verdades en power point, sino de conocer y entender la enorme complejidad de los procesos políticos, sociales, jurídicos y económicos en la experiencia del pueblo saharaui. Comprendimos que era imposible entender unos sin los otros, la interacción entre estas diversas disciplinas ha construido numerosos puentes invisibles que necesitamos descubrir y desvelar para comprender mejor el mundo que nos rodea y las distancias entre lo que se dice y se hace en materia de derechos humanos. Como Benjamin Franklin dejó escrito "Dime y lo olvido, enséñame y lo recuerdo, involúcrame y lo aprendo». ${ }^{1}$

\section{De cómo se expolian los recursos naturales del Sáhara Occidental: el derecho al servicio del poder económico}

La Real Academia de la Lengua define poder como «dominio, imperio, facultad y jurisdicción que alguien tiene para mandar o ejecutar algo». También define derecho como "conjunto de principios y normas, expresivos de una idea de justicia y de orden, que regulan las relaciones humanas en toda sociedad y cuya observancia puede ser impuesta de manera coactiva», otras acepciones añadidas serían «legítimo, fundado, cierto, razonable, justo». Por último, en lo que nos interesa para esta reflexión, en su tercera acepción define economía como «ciencia que estudia los métodos más eficaces para satisfacer las necesidades humanas materiales, mediante el empleo de bienes escasos». Pues bien, juzguen ustedes mismos las conexiones, puentes y coqueteos entre semejante trío en el caso del Sáhara Occidental, que bien deberían ser objeto de estudio académico, y dicho sea de paso, objeto de información de los medios de comunicación de masas.

Las pocas veces que aparece en los medios de información, el conflicto del Sáhara Occidental es tratado como un 
conflicto inter partes cuyo efecto principal es que casi 200.000 saharauis Ileven 36 años en los campamentos de refugiados y refugiadas en Tindouf, Argelia; lo que a renglón seguido, explica la verdadera noticia informativa, el programa «Vacaciones en Paz» que trae aproximadamente 10.000 niños saharauis a veranear en España con sus familias de acogida.

Sin embargo, hay dos enfoques claves del conflicto que nunca son visibilizados por los medios de comunicación: la expoliación de recursos naturales en los territorios ocupados, en el Sáhara Occidental, sustentada y garantizada por la ocupación ilegal del ejército marroquí; y la gravísima violación de los derechos humanos a la que es sometida la población saharaui en este territorio. Aunque consideramos que ambas situaciones están profundamente interconectadas y que son las dos caras de la misma moneda, por razones expositivas nos centraremos ahora en la primera de ellas, la expoliación de recursos naturales.

El Sáhara Occidental, y por tanto la República Arabe Saharaui Democrática, -RASD-, reconocida por casi 100 países a nivel internacional ${ }^{2}$ posee inmensas reservas de fosfatos, uno de los más importantes bancos pesqueros del Atlántico, gran cantidad de sal, arena, agua potable, etc. En su territorio se vienen realizando desde los años sesenta prospecciones de petróleo y en la actualidad ya se habla de que pudiera convertirse en el «futuro huerto solar de Africa» ${ }^{3}$. Sin embargo, como veremos a continuación, Marruecos mantiene el control de facto de los centros urbanos y económicos del Sáhara Occidental, negocia y se beneficia directamente de la extracción de estos recursos naturales, a pesar de que el Sáhara Occidental es considerado un territorio no autónomo cuya potencia administradora es España, según Naciones Unidas ${ }^{4}$.

De acuerdo con la Carta Fundacional y su Resolución 1514 (XV) de 1960 de la Asamblea General, la potencia administradora de un territorio es responsable de asegurar que cualquier beneficio económico obtenido en su colonia debe beneficiar directamente a los habitantes de dicha colonia ${ }^{5}$. En otras palabras, un país no puede explotar los recursos naturales de un territorio no autónomo sin el consentimiento de los pueblos autóctonos y sin volver a invertir los frutos de esta explotación en el propio territorio. Se debe prestar especial atención al artículo 73 de la Carta de las Naciones Unidas, puesto que del mismo se desprende que los intereses de los habitantes de estos territorios tienen prioridad absoluta y la tarea de los poderes administrativos sobre tales territorios se considera como un «deber sagrado».

En relación a los recursos naturales de carácter mineral cabe destacar que tan sólo la producción del yacimiento de Bou Craa supone una producción anual de 2,4 millones de toneladas, contribuyendo de forma sustancial a engordar los beneficios de Marruecos, concretamente en 1250 millones de euros anuales ${ }^{6}$. Además, Marruecos permite la realización de prospecciones petrolíferas en las tierras saharauis y por ello ha concedido a la empresa norteamericana Kos- 
mos Energy y Island Oil \& Gas de Irlanda licencias de explotación en la zona de Smara. ${ }^{7}$

En el mismo plano, la Resolución 1514 (XV) de la Asamblea General relativa a la cuestión de la puesta en práctica de la Declaración sobre la Concesión de Independencia a los Países y Pueblos Coloniales, hace un llamamiento a los poderes administrativos para que "garanticen que todas las actividades económicas en los territorios no autónomos bajo su administración no afecten de modo adverso a los intereses de los pueblos de dichos territorios, sino que se destinen, en su lugar, a ayudarlos en el ejercicio de su derecho a la autodeterminación $»^{8}$. Estas resoluciones también contienen disposiciones diseñadas para la protección de los «derechos inalienables de los pueblos de estos territorios a disponer de sus recursos naturales y al establecimiento y mantenimiento del control sobre el desarrollo futuro de estos recursos, además de tratar de la necesidad de proteger a los pueblos de los territorios sin gobierno autónomo de la explotación y el saqueo por parte de otros intereses económicos extranjeros». ${ }^{9}$

En definitiva, desde el punto de vista de la legislación internacional, las actividades económicas en un territorio no autónomo por parte de una potencia administradora serían legales si se realizaran en beneficio de las personas de dicho territorio, en su nombre y en consulta con sus representantes. Y el país obligado a garantizar esto es la potencia administradora, España. Por ello, es más que evidente que Marruecos carece de autoridad para dedicarse a la exploración o a la explotación de recursos minerales en Sáhara Occidental en tanto ni es potencia administradora, ni tiene en cuenta los intereses y los deseos del pueblo del Sáhara Occidental. Como indica uno de los principales lemas en las denuncias de los movimientos sociales «Marruecos culpable, España responsable», aludiendo a la innegable responsabilidad jurídica de nuestro estado.

Sin embargo, la Comisión Europea firmó un Acuerdo de Asociación Pesquero con Marruecos en mayo de 2006 que se aplica, en principio, a las zonas de pesca marroquíes, lo que viene pues a referirse, a las aguas bajo soberanía o jurisdicción del reino de Marruecos. No obstante en dicho acuerdo no se hace distinción alguna en relación a las aguas adyacentes del Sáhara Occidental. La ilegalidad de este Acuerdo de la Unión Europea con Marruecos resulta obvia si nos detenemos en el Protocolo del Acuerdo. Este documento hace referencia en exclusividad a los «recursos de Marruecos», en su artículo 4. En relación a la contribución financiera, el Protocolo afirma en su artículo 6 que «se dejará a la entera discreción de las autoridades marroquíes el uso de esa contribución financiera». Este mismo artículo establece, de manera prescriptiva, en una larga enumeración cómo debe asignarse la contribución y en ella es muy difícil identificar a los saharauis. El protocolo menciona a lo largo de su articulado y en su propio apéndice «la industria pesquera marroquí» "la zona Atlántica marroquí», los "marineros marroquíes» y los «puertos marroquíes». Aunque la clave reside sin duda en el 
Apéndice 4, en el que se explicita los límites de las zonas pesqueras marroquíes. Concretamente establece para la pesca del atún las coordenadas limitadoras en el sur de «al sur de $29^{\circ} 00^{\prime} »^{10}$, lo que incluye, como era de sospechar, las aguas del Sáhara Occidental. De este modo, el acuerdo deja la puerta abierta a la pesca en las aguas territoriales saharauis, puesto que la interpretación de la fórmula en coordenadas entiende todas las aguas hacia el sur, hasta donde comienzan las de Mauritania, aproximadamente a $21^{\circ} \mathrm{N}$.

En relación con la explotación de los recursos pesqueros, según un Informe Marco General elaborado por la embajada de España en Rabat en 2009, el «sector pesquero marroquí» alcanzó un volumen de negocios de más de 706 millones de euros. Las cifras van ascendiendo el volumen total de capturas en 2008 a 1.017.027 toneladas, aumentando un $24 \%$ su valor respecto al año 2007, un año posterior a la entrada en vigor del Acuerdo Pesquero con la Unión Europea. Por otro lado, en relación con valor de los desembarques de este segmento registrados en los mercados se contabilizó 432 millones de euros, frente a los 351 millones de euros del año anterior, conllevando entonces un aumento del 23\%. Del mismo modo, se confirmó que la pesca costera y artesanal representa más de $94 \%$ en volumen total. El puerto del Aaiún registró el año 2007 casi la mitad de los desembarcos de pesca controlados desde Marruecos. Las empresas españolas también tienen sus propios intereses como es el caso de Europacífico, que tiene socios japoneses, chilenos y neerlandeses, y firmó el año 2008 un acuerdo para distribuir 30.000 toneladas de pescado saharauii ${ }^{11}$.

La Carta de las Naciones Unidas es sin duda el eje vertebrador del Derecho Internacional y sus Leyes, y según su artículo 103, la carta tiene básicamente primacía sobre otros acuerdos internacionales en caso de conflicto entre dichos acuerdos y aquélla. Por tanto, jurídicamente hay mecanismos más que suficientes para paralizar la expoliación de recursos. Sin embargo, de nuevo podemos ver la flagrante violación del Derecho Internacional, esta vez a cargo de la UE, una de las principales instituciones que promueve su cumplimiento. No en vano, Marruecos es el país del mundo que más resoluciones de Naciones Unidas vulnera, después de Israel.

Nos topamos con la «realpolitik»: el capitalismo como sistema de mercado y el neoliberalismo como ideología sostienen a este mundo tal y como lo conocemos. De este modo, nos preguntamos en qué medida estas instituciones supranacionales son utilizadas y/o están al servicio de los intereses determinados por el poder económico. Un poder económico que usa el derecho, el propio acuerdo pesquero, para terminar compartiendo con los poderes políticos un muy rentable sentido de la justicia.

Nada nuevo, pensarán ustedes, a poco que conozcamos la fundamentación filosófica del neoliberalismo y los mecanismos institucionales a través de los cuales opera. Lo preocupante, desde nuestra percepción como estudiantes, ocurre cuando desde el propio sistema educativo y el pensamiento político, 
como sucede con los medios de comunicación, «la mano invisible» se hace más invisible y más incuestionable que nunca al desconocer e ignorar precisamente los vínculos y las superposiciones entre lo que estudiamos como diferentes disciplinas auto-referenciadas e independientes, de manera complaciente. ¿Hasta qué punto está la educación también está sustentada y sustentando este pensamiento neoliberal, el pensamiento único? ¿Ocurre una producción en masa de mentes sumisas e incapaces de pensar y conocer alternativas? ¿Por qué los alumnos y alumnas nos sentimos en una cadena de montaje fordista del conocimiento? ¿Por qué el sistema educativo no suele trabajar con los nombres de las empresas beneficiadas por tan sui generis ejercicio del derecho?

\section{De cómo el derecho, el poder, la economía y la política construyen la cotidianidad saharaui: de la tortura del tiempo a la tortura de los cuerpos}

Llevábamos ya meses profundizando sobre la situación del pueblo saharaui y sus diversas causas, cuando se planteó la posibilidad de realizar una primera toma de contacto en el terreno, visitar, conocer y llevar a cabo las primeras entrevistas en los campamentos de refugiados y refugiadas saharauis en Tindouf. Se pueden imaginar la ilusión y la expectativa que esta noticia causó en el grupo, ya no solo sería una experiencia de aprendizaje en la distancia, sino que podríamos escuchar, tocar, ver y sentir todo aquello que leíamos. Después de muchas reuniones, informes y explicaciones, conseguimos el apoyo del equipo rectoral, del decanato y del área de filosofía del derecho y nos dispusimos a realizar el desplazamiento.

Era Semana Santa, y sin duda viajábamos hacia el contraste. Directos a la cara oculta de la historia de la civilización europea. Los campos de refugiados y refugiadas saharauis en Tindouf, esperándonos para tambalear las recién adquiridas verdades científicas de un grupo de universitarios/as europeos/as, blancos/as, de clase media, que estudian derecho y políticas «para transformar el mundo». Aún recordamos las intensas sensaciones previas al viaje. Una vez que descubres y vivencias realidades humanas impensables y desconocidas en las aulas, es difícil volver a admitir el pensamiento político, sin que ellos y ellas sean el centro, y no la periferia. Hay experiencias que aportan sentido al ritmo vital de cada uno, y esta ha sido sin duda una de ellas. Hay aprendizajes que humanizan profundamente.

Diez días de estancia en los campamentos, especialmente en el campamento de Dajla, y 16 entrevistas: dos ministras, tres médicos, una cooperante, una jueza, el director de los huertos comunitarios, el responsable de cultura, la directora de la escuela de educación especial, el gobernador provincial, la secretaria general de la Unión Nacional de Mujeres Saharauis (UNMS), cuatro representantes de la Unión Nacional de 
Jóvenes Saharauis (UJSARIO), etc. y las visitas al museo de la resistencia, los huertos, hospitales, escuelas de primaria, secundaria y educación especial, casa de la mujer, centros de jóvenes...

No fue difícil comprender por qué los campamentos de refugiados y refugiadas saharauis en Tindouf eran los mejor gestionados del mundo, según los organismos internacionales, y reconocidos como un ejemplo de buenas prácticas de emancipación social a nivel internacional. Estos campamentos han llegado a alcanzar niveles de alfabetización y sanidad impensables en su contexto africano. De pronto, comprendimos que el acumulado de conocimiento y experticia política del pueblo saharaui, que levantó un estado en pleno desierto, en el exilio y en guerra, la República Árabe Saharaui Democrática. Esto era algo que, sencillamente, nuestro entorno ignoraba. Ibamos allí para aprender de y con ellos, pero no lo supimos hasta más tarde.

Sin embargo, al visitar los campamentos y conversar con su gente, se produjo otro giro aún más insospechado sobre nuestra novedosa lectura de la realidad política. Descubrimos la importancia de las señales que la política, el derecho y la economía marcan en los cuerpos mediante el ejercicio del poder. Descubrimos la capacidad de la lucha política de los y las saharauis para desvelar el cúmulo de opresiones articuladas en torno a sus cuerpos y a sus riquezas naturales.

Más allá de las entrevistas realizadas en el ámbito institucional y sus discursos más o menos oficialistas, compartimos interesantes reflexiones y encuentros con las familias en cuyas jaimas nos alojábamos, con padres y madres, con jóvenes, con niños y niñas saharauis... Con ellos y ellas llegó la dimensión de la cotidianidad, lo que significa ser refugiado/a político/a en la zona más inhóspita del desierto, la hammada, con temperaturas que van de los $58^{\circ}$ grados en verano $a-1^{\circ}$ en el invierno. Lo que significa llevar 35 años esperando que las resoluciones de la ONU superen la barrera de la retórica, mientras la canasta básica del plan mundial de alimentos no llega al día veinte del mes y la expoliación de recursos en el Sáhara Occidental es auspiciada y financiada por la Unión Europea. Fue entonces cuando descubrimos la memoria colectiva de un pueblo que sobrevive a base no poder olvidar el dolor salpicado en los bombardeos con fósforo blanco y napalm sobre las hileras de personas aterradas que huían por el desierto en el año 75, meses después de la invasión marroquí iniciada con la marcha verde. Así llegaron a Tindouf, el refugio, donde se alzaron los campamentos desde lo que algunos filósofos Ilamarían la nuda vida.

Es curioso, el pueblo saharaui es un pueblo que sobrevivió en un verdadero estado de naturaleza. Un pueblo que se reinventó a si mismo desde un nuevo contrato social propuesto por la revolución, de indudable calado igualitarista y basado en la justicia social. Sin embargo, a pesar de su lealtad a la mitología democrática, la RASD no es reconocida actualmente por ningún gobierno europeo. ¿Cuántos estados de naturaleza ficticios necesitó inventar la teoría contrac- 
tualista? ¿Cuántos estados de naturaleza experimentados y percibidos como emancipatorios por comunidades humanas necesita ignorar nuestro pensamiento político?

Fue entonces cuando entrevista tras entrevista, comenzamos a aprehender la crudeza de la situación actual, tras 21 años sin guerra, tras 21 años sin paz $^{12}$. Las condiciones alimenticias, el difícil acceso al agua, la ausencia de médicos, los problemas de anemia, la fuga de cerebros, la separación de las familias de los jóvenes que salen a estudiar fuera, los silencios de los niñas y niñas que retornan del verano en España... La tragedia de una generación que vivió el horror de la guerra, nos decían: «quien conoce la guerra, no desea volver a vivirla». La desesperación de otra que está dispuesta a lo que sea. Cuando no se tiene futuro, la sola vida se convierte en la única posibilidad, el único bien sobre el que poder decidir. Cuándo morir es la única forma de poder resucitar como pueblo, y seguir vivo en los campamentos es una forma de muerte, no hay teoría que lo soporte. Ya lo dejó claro el subcomandante Marcos. Mientras tanto, la comunidad internacional y su cooperación siguen confundiendo humanitarismo con justicia y alimentos con derechos. Seguimos informando sobre conflictos inter partes, cuando realmente hablamos de conflictos producidos por desequilibrios estructurales de poder y derechos en contextos de des(neo)colonización. Nos relataba Tiba, el director de cultura en Dajla, sobre la incuestionable consciencia política del pueblo saharaui:
«... hay españoles que creen que dándonos un litro de aceite o ayudando a la caravana alimentaria que se hace anualmente para el pueblo saharaui... creen que ya tienen la conciencia tranquila... No es lo que necesitamos, no es que nos hace falta, sí nos hace falta mucho, pero poniendo en prioridad, nos gustaría resolver nuestro problema... la palabra refugiados... no somos refugiados de una hambruna, no somos refugiados de una causa sobrenatural, somos refugiados de una causa política, y si no nos dan harina y nos resuelven nuestro problema estaremos a gusto porque hemos vivido sabiendo que vamos a un desierto, que vamos a sufrir, que vamos a pasar hambre, pero por un objetivo, y antes de lograr este objetivo, no descansaremos"

Es imposible hacer en este testimonio una exposición de todas y cada una de las entrevistas, pero sin lugar a dudas hubo otra realmente impactante. Con motivo del Fisahara 2011 (festival de cine que se realiza cada año en los campamentos de refugiados y refugiadas saharauis) visitaban los campamentos la $11^{a}$ Comisión de Activistas de Derechos Humanos procedentes del otro lado del muro, de los territorios ocupados. Tras un encuentro con ellos de dos horas, aprendimos algo en apariencia obvio, pero que nunca forma parte de la teoría política. Qué es ser un activista en derechos humanos, a qué se enfrentan y por qué. Activistas de derechos humanos, es decir, personas cuyos cuerpos han sido y están siendo sistemáticamente increpados, torturados, violados, amenazados... e incluso encarcelados durante decenas de años por defender pública y pacíficamente el derecho de 
autodeterminación del pueblo saharaui y denunciar la expoliación de los recursos naturales en el Sáhara Occidental. Todas ellas recién llegadas de los territorios ocupados, el lugar que contiene las riquezas con las que el derecho internacional se encarga de decir y hacer lo contario. De nuevo, juzguen ustedes mismos.

El 25 de noviembre de 2009, la revista digital El Observador publicó un reportaje en el que afirmaba que en el Sáhara Occidental, en los territorios ocupados, se violan los treinta artículos de la Declaración Universal de los Derechos Humanos de 1948. Basándose en testimonios de saharauis que fueron testigos o víctimas de los mismos y apoyándose en informes de Human Right Watch, Amnistía Internacional, Reporteros Sin Fronteras y otras organizaciones, compiló una serie de evidencias que ponen de manifiesto lo siguiente: no se respetan los Derechos Humanos en el Sahara Occidental ocupado por Marruecos. Desde 1975 los saharauis han sido perseguidos y hostigados por las fuerzas del Reino de Marruecos. Muchos, huyendo del fósforo blanco y el napalm, se refugiaron en Argelia. Sin embargo, recientemente, se han encontrado los restos de quienes no tuvieron la misma suerte: fosas comunes con enterrados vivos y personas lanzadas al vacío desde los helicópteros de las Reales Fuerzas Armadas Marroquíes muestran la brutalidad existente desde el primer momento. ${ }^{13}$

Otro elemento importante de este régimen de terror son las desapariciones, detenciones ilegales de personas a quie- nes no se vuelve a ver. Al desaparecido se le da por muerto y sus familias quedan para siempre estigmatizadas socialmente. No solo pierden a un familiar sino que no pueden hablar de ello. ${ }^{14}$ En el caso de las detenciones, se producen de manera arbitraria e ilegal con total impunidad. Aunque el Código Penal marroquí impone la obligación de avisar a la familia del detenido - de lo contrario el agente de policía está cometiendo un delito de secuestro- es un requisito comúnmente no respetado. En otros casos, durante estas detenciones, que suelen abusar de la prisión preventiva llegando a durar años, y tras condenas de cárcel, se dan casos sistemáticos de tortura y tratos degradantes, lo que es aprovechado por las autoridades para obligar a los presos a firmar declaraciones de culpabilidad bajo violencia o intimidación. ${ }^{15}$ Las modalidades de torturas más comunes son la introducción de botellas de Coca Cola en el ano, golpes, arrancado de uñas, corriente eléctrica en los genitales, inmersión de la cabeza hasta la asfixia en una piscina de agua acidificada y excrementos, etc. ${ }^{16}$

Todo esto nos fue relatado en aquellas dos horas, en una clase magistral sobre resistencia y práctica política. Sentados en círculo y escuchándoles, fue inevitable que como estudiantes de políticas, como futuros juristas, todo lo que habíamos aprendido sobre la abstracta doctrina iusnaturalista de los derechos humanos quedara en suspenso. En aquel círculo había una joven saharaui, la cual acababa de salir de la cárcel negra de El Aiún, donde tras haber recibido numerosas palizas fue sometida a violaciones grupales por la policía ma- 
rroquí. Con todo el dolor, con el peso de lo vivido, con la carga de la responsabilidad de ser saharaui en los territorios ocupados, allí estaba, contándonos a un grupo de estudiantes occidentales de ciencia política y derecho qué significa resistencia real y corporal a las políticas neoliberales ejecutadas por el ejército del reino alauita, socio preferente de la Unión Europea. Escuchando a aquellos que viven ignorados por el derecho internacional que aprendemos en las aulas, nos preguntamos al servicio de qué, de quién, está entonces esta doctrina.

En otra ocasión visitamos la sede de la Asociación de Familiares de Presos y Desaparecidos Saharauis -AFAPREDE$S A-$, uno de los colectivos que se encargan de denunciar estos abusos. ${ }^{17}$

Nos relataron cómo parte de su trabajo consiste en investigar las desapariciones que se vienen produciendo desde los años setenta, identificar a personas que vivieron en aquélla época, conseguir que hablen de experiencias traumáticas, rastrear los nombres que recuerdan y saber qué fue de ellos. Del mismo modo, contribuyen de una forma especial a la labor de sensibilización con exposiciones, como la que tuvimos ocasión de ver, mostrando documentos gráficos de las torturas sufridas por saharauis y participando en documentales como «El Problema» ${ }^{18}$. En esta misma línea, también es relevante la labor de organizaciones como el Colectivo de Defensores Saharauis de los Derechos Humanos -CODESA-, la Asociación de Saharauis Víctimas de Graves Violaciones de los Derechos Humanos -ASVDH-, o la Asociación Marroquí de
Derechos Humanos -AMHD-. Esta última, formada por marroquíes, hace una importante labor de contestación y lucha pacífica al régimen marroquí. Como asociación defensora de los derechos humanos no sólo han registrado los abusos cometidos en los territorios ocupados, sino que aboga por una solución pacífica y democrática al conflicto por el Sáhara, de modo que termine el sufrimiento de ambos pueblos. ${ }^{19}$

Aquéllos detenidos saharauis que son llevados ante el juez por expresar pública y pacíficamente su condición de saharauis, tampoco tienen más suerte. Los juicios a los que someten a los ciudadanos saharauis a menudo no son más que una pantomima donde lo que más brilla por su ausencia es la justicia. Son muchas las organizaciones que envían observadores a estos procesos judiciales y sus informes no tienen desperdicio. El informe de la Comisión Derechos Humanos del Consejo General de la Abogacía Española -CGAE- ha puesto de manifiesto la parcialidad de sus jueces y el carácter «inquisitorial» de la fiscalía. ${ }^{20}$ Del mismo modo, han documentado sucesos poco ortodoxos. Como muestra, decir que Naama Safari, copresidente del Comité para el Respeto de las Libertades y los Derechos humanos en el Sáhara, acudió al juicio de apelación celebrado en el Tribunal Penal de Marrakech en 2008. Fue obligado a declarar en ropa interior.

En cuanto a las libertades públicas, ya de por sí bastante socavadas en el reino alauita, son sistemáticamente pisoteadas en el caso de la población saharaui. Human Right Watch, en el capítulo de- 
dicado a Marruecos y el Sáhara Occidental, en su Informe Mundial 2010, describe los problemas que tienen varios colectivos para convertirse en asociaciones. Además de a los saharauis, la burocracia marroquí deniega el permiso a la población imazighen (bereber), inmigrantes subsaharianos y universitarios desempleados, además de algunos movimientos islamistas. ${ }^{21}$ En cuanto a la libertad de expresión y de prensa, en teoría está todo permitido excepto tocar tres temas «tabú»: la monarquía, el Islam y la integridad territorial. Reporteros Sin Fronteras ha mostrado su indignación no sólo con la denegación de acceso a periodistas a zonas como El Aaiún, sino la extrema suavidad del gobierno español para con quienes censuran a sus ciudadanos. Por otra parte, Al Jazeera ha cerrado su sede en Marruecos acosada por las trabas administrativas y gubernativas, por dar, según Marruecos, una visión sesgada del Reino y «su integridad territorial», en referencia a la cuestión del Sáhara Occidental.

El informe del CGAE anteriormente citado describe como durante el juicio a siete activistas pro-derechos Humanos, entre ellos, Haminetu Haidar, conocida como la Gandhi saharaui, al inicio de una de las sesiones había llegado todo el mundo menos los acusados, que seguían en prisión preventiva. Cuando la defensa preguntó al tribunal por qué no los habían traído, éste contestó con evasivas. Ante la vehemencia de los abogados, el presidente del tribunal preguntó al Procurador del Rey (fiscal) sobre este hecho, ya que es el encargado de los movimientos de los acusados. Entonces, «al ser requerido por el presidente, mira al techo y no hace ningún comentario, permaneciendo callado». Al exigir la defensa responsabilidades ante tamaño desatino, ocurre lo siguiente: «El Tribunal no contesta, se levantan los magistrados de forma precipitada y salen de la sala a toda prisa sin explicación alguna». ${ }^{22}$

Otra forma de opresión que ejerce el Reino de Marruecos y que consideramos importante es la referente a la libertad de circulación. Además de los impedimentos burocráticos y judiciales a los que ya hemos aludido, debemos hacer mención a una obra lamentable, un símbolo arquitectónico que muestra lo peor de la ingeniería militar: el Muro de la Vergüenza. Una muralla de unos 2720 kms. vigilada constantemente por cientos de miles de soldados ${ }^{23}$, rodeada de nueve millones de minas anti-personas (para un pueblo de medio millón de personas) y de miles de sistemas de vigilancia, incluyendo radares y baterías de posición. Un muro que comenzó a construirse en los años 80, dividiendo en dos al pueblo saharaui y garantizando la explotación de los recursos naturales por parte de Marruecos.

En la visita realizada al Museo Nacional de la Resistencia Saharaui, en Rabouni, pudimos recibir una exhaustiva explicación sobre el tema. Sorprende, por ejemplo, que Marruecos ande siempre pidiendo ayuda económica a sus socios occidentales para mejorar la estabilidad de la región, sabiendo que mantener el muro le cuesta cuatro millones de dólares al día. Parte de la financiación proviene de los fondos europeos para com- 
batir la inmigración ilegal. Un vistazo a su octava sala sirve para comprobar que hay aviones bombarderos de fabricación francesa con bandera marroquí o artillería británica entregada a Marruecos por la OTAN. Y, obvio, fueron utilizados para eliminar saharauis. Recordemos que en la actualidad España es la octava potencia del mundo en la venta de armas y que uno de sus principales clientes es Marruecos ${ }^{24}$. Las conclusiones no son complicadas.

Financiar una tentativa de genocidio a cambio de acceso a recursos naturales y dominio geoestratégico es algo que no trasciende a la opinión pública, pero que existe. Ya hay interpuestos procesos judiciales, concretamente demandas por genocidio y ventas de armas, en este sentido. Queda patente que la problemática del Sáhara Occidental es un caso de expoliación de recursos flagrante, cuyos principales costes son los propios cuerpos, las vidas dignas de ser vividas de la población saharaui. Cuerpos refugiados y encarcelados en la prisión del tiempo ${ }^{25}$ de un lado del muro; cuerpos torturados y desaparecidos, del otro.

En el Campamento de Dajla tuvimos la oportunidad de escuchar a Francesco Bastari, quien fue Representante Especial de Naciones Unidas para el Sahara Occidental hasta 1996. Probablemente él conozca mejor que nadie la situación del Sáhara Occidental en relación con los movimientos de Naciones Unidas y los estados implicados en esta cuestión. Mostró públicamente su profunda vergüenza acerca de la inactividad de la ONU y la inutilidad de la Misión de Naciones Unidas para el Referéndum en el Sáhara Occidental -MINURSO- . Su incompetencia, explicaba, reside en el hecho de que el mandato otorgado por la ONU a esta misión se dirige exclusivamente a realizar el referéndum y a vigilar el alto el fuego, nada sobre salvaguardar los derechos humanos. Cuando se ha intentado, por ejemplo, asistir a la población civil en el desierto, Marruecos ha protestado alegando que se está extralimitando en sus competencias. En abril de 2011 la ONU ha renovado el mandato de la MINURSO, incomprensiblemente, de nuevo, sin otorgarle competencias para proteger los derechos humanos de la población saharaui. Como el proceso de referéndum está bloqueado y el Principio de No Injerencia en los Asuntos Internos le «impide» a la MINURSO defender a los civiles ante abusos de las partes la misión, nos preguntamos cuál es entonces el sentido de su presencia en la zona. Dado que las resoluciones de la Asamblea General no son respetadas por Marruecos y que el Plan Baker (en sus distintas manifestaciones) fue un fracaso, Basari propone usar otros recursos:

«... a nivel de la ONU, utilizar la Asamblea General, formada en su mayoría por Estados surgidos de la descolonización, para dictar resoluciones que presionen en el plano internacional; el pueblo saharaui debe fijarse su objetivo en el largo plazo con etapas intermedias de conquistas concretas; y finalmente, hay que recurrir al apoyo que tiene el pueblo saharaui en la sociedad civil para presionar mediante la opinión pública internacional»

La pregunta a Bastari sería entonces si podemos estar hablando de 35 años más. Nos tememos que sí. 
Y no es que desde el grupo de estudios tengamos soluciones o propuestas frente a los altos cargos de la ONU. Además de la evidente ausencia de conocimiento que a todas y todas aún nos acompaña sobre un tema tan complejo, el atrevimiento de hacerlo supondría invadir un espacio que corresponde a otros y otras, cuya cotidianidad les otorga la legitimidad y el conocimiento necesario para elegir. Nos queda el profundo convencimiento de que es el propio pueblo saharaui quien debe decidir sobre su futuro y sobre las posibles maneras de construirlo. Reconocerles su legitimidad como pueblo y por tanto su agencia política; trascendiendo discursos paternalistas que presuponen su minoría de edad en la arena internacional, quizás sea la mejor contribución que desde la academia y el pensamiento político podamos hacer a esta causa.
Consideramos que somos un grupo de jóvenes estudiantes que, también como seres humanos, han descubierto «las reglas del juego» junto a otras personas, los y las saharauis, que ya las conocían mucho antes. Aprender en el reconocimiento de los demás, de su agencia política y en el ejercicio de la otredad, ha sido el comienzo para aprender a aprender de otro modo. Si en los seminarios de investigación y estudios sobre la causa saharaui intuimos el error de intentar pensar y analizar el derecho, la política y la economía de manera independiente, el trabajo de campo en los campamentos nos hizo dar un paso más allá. Quizás nunca más pensemos el derecho, la política y la economía, sin pensar en los cuerpos, en las señales que el poder deja.

\section{Notas}

${ }^{1}$ Franklin, B. (2007). Autobiografía. Sevilla. Mono Azul Editora.

${ }^{2}$ A pesar de ser reconocida como miembro de la Unidad Africana -UA- y por numerosos países latinoamericanos, ningún país en Europa reconoce la RASD, proclamada el 27 de febrero de 1976.

3 "El futuro huerto solar de Africa», El observador. Revista de Culturas Urbanas, 52, 2008.

${ }^{4}$ En la web oficial de Naciones Unidas, en su listado de territorios no autónomos, hay una cita 2 que en cuanto a la administración del Sáhara Occidental, aclara literalmente: « El 26 de febrero de 1976, España comunicó al Secretario General que a partir de dicha fecha daba por terminada su presencia en el Territorio del Sáhara y que estimaba nece- sario hacer constar lo siguiente: España se consideraba a partir de ese momento exenta de toda responsabilidad de carácter internacional en relación con la administración del Territorio, en vista de que había cesado su participación en la administración temporal establecida para el Territorio. En 1990 la Asamblea General reafirmó que la cuestión del Sáhara Occidental era un problema de descolonización que debía ser resuelto por el pueblo del Sáhara Occidental», ver en <http://www.un.org/es/decolonization/ nonselfgovterritories.shtml>, 29/10/2011.

518 de febrero de 1999, RESOLUCIÓN APROBADA POR LA ASAMBLEA GENERAL DE LA ONU [sobre la base del informe de la Comisión Política Especial y de Descolonización (Cuarta Comisión) (A/53/602)] 53/61. 
Actividades económicas y de otro tipo que afectan a los intereses de los pueblos de los territorios no autónomos.

6 http://www.eleconomista.es/internacional/ noticias/2602059/11/10/son-los-fosfatosestupido-.html, 29/10/2011

7 El observador. Revista de Culturas Urbanas, 52, 2008

8 Oficina del Alto Comisionado de las Naciones Unidas para los derechos Humanos, <http://www2.ohchr.org/spanish/law/ independencia.htm>, 29/10/2011

924 de enero de 2000. RESOLUCIÓN APROBADA POR LA ASAMBLEA GENERAL [sin remisión previa a una Comisión Principal (A) 54/L.50 y Add.1)] 54/91. Aplicación de la Declaración sobre la concesión de la independencia a los países y pueblos coloniales. 10 2006. Diario Oficial de la Unión Europea. Acuerdo de colaboración en el sector pesquero entre la Comunidad Europea y el Reino de Marruecos.

${ }^{11}$ Red de Oficinas Económicas y Comerciales de España en el Exterior. Secretaría de Estado de Comercio Exterior. 2009, Informe Marco General institucional, político y económico del país. Análisis de coyuntura. Cuestiones multilaterales.

12 Recordemos que el alto el fuego, auspiciado por la Organización de la Unidad Africana OUA y la ONU, fue firmado en 1991

${ }^{13}$ Situación de los Derechos Humanos en el Sáhara Occidental», en Memoria Anual de la Asociación para el Referéndum en el Sáhara Occidental, 2002
${ }^{14}$ Para ver una lista de los desaparecidos saharauis desde 1975, ver en http://www. desaparecidos.org/sahara/lista.html, 19/10/ 2011

15 Informe sobre el Estado de los Derechos Humanos en el Mundo, 2011, Amnistía Internacional

${ }^{16}$ Asociación por el Referéndum en el Sáhara Occidental -ARSO-, ver en http:// www.arso.org/DHSamemo2002s.htm

17 http://www.afapredesa.org/

18 Documental dirigido por Jordi Ferrer y Pablo Vidal, ver en www.elproblema.net

19 V.V.A.A. (2009) Universidad y Sáhara Occidental: Reflexiones para la Solución de un Conflicto; Cuadernos Solidarios $n^{\circ}$ 6, UAM, Ediciones, Madrid.

20 VVAA (2005), Informe de la Misión de Observación del CGAE, en Juicios contra Presos Políticos en el Sahara Occidental; Comisión de Derechos Humanos del Consejo General de la Abogacía de España

21 http://www.hrw.org/es/world-report-2011/ marruecos-y-el-s-hara-occidental, 16/10/ 2011.

22 VVAA. (2005), Informe de la Misión de Observación del CGAE, en Juicios contra Presos Políticos en el Sahara Occidental; Comisión de Derechos Humanos del Consejo General de la Abogacía de España.

23 Minaham, J. (2002) Encyclopedia of Staless Nations: S-Z, GreenWood Publishing Groop, Westport

24 «España ha vendido armamento bélico a Marruecos por 340 millones de euros», en <http://www.antimilitaristas.org/spip. php?article4710>, 16/10/2010. 